\title{
Commentary The impact of critical care outreach: is there one?
} Brian H Cuthbertson

\begin{abstract}
Clinical Senior Lecturer in Critical Care and Consultant in Intensive Care Medicine, Health Services Research Unit, Health Sciences Building, University of Aberdeen, Foresterhill, Aberdeen AB25 2ZD, UK
\end{abstract}

Corresponding author: Brian H Cuthbertson, b.h.cuthbertson@abdn.ac.uk

Published: 30 November 2007

This article is online at http://ccforum.com/content/11/6/179

(C) 2007 BioMed Central Ltd

See related research by Gao et al., http://ccforum.com/content/11/5/R113
Critical Care 2007, 11:179 (doi:10.1186/cc6179)

using a randomised controlled trial design, and some proponents seemed to believe that supportive evidence was not required at all [1].

An evaluation of critical care outreach services was published in the previous issue of Critical Care that fails to demonstrate any important outcome benefit associated with these services. It is now time to ask some difficult questions about the future of outreach, including whether the lack of evidence should lead to disinvestment in such services.

Medical emergency teams (METs) and critical care outreach are no longer new ideas [1]. The services were founded in Australia in the 1990s with the concept of METs using the well-recognised principle that early recognition and aggressive intervention improves outcome from critical illness [2]. The systems have now developed into a variety of incarnations around the globe - becoming critical care outreach services (CCOS) in the United Kingdom, and the rapid response teams in North America [3-5]. Although there are some differences between these services, they all have the same primary aim of preventing critical illness with its associated morbidity and mortality.

CCOS losing its youth produces an urgent requirement for efficacy and cost-effectiveness to be demonstrated. The most detailed evaluation to date of these systems is the MERIT study from Australia, which was a multicentre cluster randomised trial of METs [6]. Sadly, the study failed to demonstrate a reduction in intensive care unit (ICU) admissions, cardiac arrests or inhospital mortality. There are some weaknesses in the trial but it still represents by far the highest level of evidence to date on METs/CCOS. The publication of this disappointing result led to a rapid distancing of CCOS from their MET parent, clearly fearing that this result would tarnish their new-found status. Indeed, since the publication of the MERIT study, proponents of CCOS have commonly stated that CCOS cannot be tested
Thankfully, in the previous issue of Critical Care a detailed evaluation of CCOS in the United Kingdom from a group based at the Intensive Care National Audit \& Research Centre in London was published [1]. In the paper the authors restate the principle that 'CCOS cannot now be evaluated using the gold-standard research design, a multicentre, randomised controlled trial', and instead one must use an interrupted time-series method. The analysis was performed on the Intensive Care National Audit \& Research Centre case-mix programme (a high-quality clinical database of nearly 400,000 ICU admissions) and on data taken from a large national survey of CCOS. A range of outcomes designed to 'reflect the CCOS objectives of averting admissions, ensuring timely admission and enabling discharge were investigated', including the proportion of admissions direct from wards, the length of ICU stay, ICU mortality and hospital mortality. Sadly, despite reductions in cardiopulmonary resuscitation rates and physiological disturbance in the time before ICU admission, CCOS were not associated with an improvement in ICU mortality or hospital mortality $[7,8]$. Further, the authors were unable to identify which of the many highly variable operational characteristics of the CCOS were optimal. Interestingly, they observed that there was no 'dose-response' relationship for CCOS that could have implied that the greater the CCOS coverage, the better the outcomes that can be achieved. Finally, the authors observed that '... changes in admission characteristics may be attributable in part to the use of physiological track and trigger warning systems', despite the fact that this group's previous work demonstrated very poor sensitivity and specificity for such scores [9].

$\mathrm{CCOS}=$ critical care outreach services; ICU = intensive care unit; MET = medical emergency team. 
So where does this leave us with regard to future of CCOS in the United Kingdom and beyond? The continued inability of studies to demonstrate the efficacy of CCOS and a complete lack of evidence for cost-effectiveness is worrying. A recent guideline by the National Institute for Health and Clinical Excellence on the management of the acutely ill hospital patient was unable to recommend outreach services due to a lack of supportive evidence [10]. The National Institute for Health and Clinical Excellence did feel able to recommend the use of early warning scoring systems but was unable to identify a particular system or cutoff points due to the lack of evidence of accuracy for these scores in clinical practice [9]. Despite the lack of evidence, the Institute of Healthcare Improvement recommends 'deploying rapid response teams' as one of their 12 interventions 'proven to prevent morbidity and mortality' in their 100,000 lives campaign [10]. The Institute of Healthcare Improvement clearly has access to an evidence base that the rest of us do not.

There are therefore many questions to be answered:

1. Do early warning systems actually allow early identification of sick patients, or are their diagnostic accuracies too low to justify use in clinical practice?

2. Is there an optimal configuration for CCOS that can actually lead to an improvement in important patientbased outcomes?

3. If CCOS can be demonstrated to be efficacious will it prove to be cost-effective?

4. Should countries that fund CCOS now disinvest and spend these resources in more effective ways?

It is time to answer these difficult questions!

\section{Competing interests}

The author declares that they have no competing interests.

\section{References}

1. Gao H, Harrison DA, Parry GJ, Daly K, Subbe CP, Rowan K: The impact of the introduction of critical care outreach services in England: a multicentre interrupted time-series analysis. Crit Care 2007, 11:R113.

2. Lee A, Bishop G, Hillman KM, Daffurn K: The medical emergency team. Anaesth Intensive Care 1995, 23:183-186.

3. Department of Health: Comprehensive Critical Care: A Review of Adult Critical Care Services. London: Department of Health; 2000.

4. Department of Health and NHS Modernisation Agency: The National Outreach Report 2003. London: Department of Health; 2003.

5. Devita MA, Bellomo R, Hillman K, Kellum J, Rotondi A, Teres D, Auerbach A, Chen WJ, Duncan K, Kenward G, et al.: Findings of the First Consensus Conference on Medical Emergency Teams. Crit Care Med 2006, 34:2463-2478.

6. Merit Study Investigators: Introduction of the medical emergency team (MET) system: a cluster-randomised controlled trial. Lancet 2005, 365:2091-2097.

7. Bellomo R, Goldsmith D, Uchino S, Buckmaster J, Hart GK, Opdam H, Silvester W, Doolan L, Gutteridge G: A prospective before-and-after trial of a medical emergency team. Med $J$ Aust 2003, 179:283-287.

8. Buist MD, Moore GE, Bernard SA, Waxman BP, Anderson JN, Nguyen TV: Effects of a medical emergency team on reduction of incidence of and mortality from unexpected cardiac arrests in hospital: preliminary study. BMJ 2002, 324:387-390.

9. Gao H, McDonnell A, Harrison DA, Moore T, Adam S, Daly K, Esmonde L, Goldhill DR, Parry GJ, Rashidian A, et al.: Systematic review and evaluation of physiological track and trigger warning systems for identifying at-risk patients on the ward. Intensive Care Med 2007, 33:667-679.

10. Institute of Healthcare Improvement $-100,000$ lives campaign [http://www.ihi.org/IHI/Programs/Campaign/ Campaign.htm?Tabld= 2\#InterventionMaterials] 